\title{
EL MARCO JURÍDICO DE LAS PERSONAS QUE PARTICIPAN EN ACTOS DE VIOLENCIA. UNA RESPUESTA DESDE EL DERECHO INTERNACIONAL
}

\author{
César A. Villegas Delgado*
}

\begin{abstract}
RESUMEN: La implacable "Guerra mundial contra el terrorismo", encabezada por los Estados Unidos de América tras los acontecimientos del 11-S de 2001, ha sido fuente de importantes consecuencias negativas para la protección de los derechos humanos fundamentales. La aprobación o aplicación de leyes y políticas antiterroristas al margen de la legalidad y del Estado de derecho a nivel internacional potencia, a su vez, el riesgo de traicionar la causa de la justicia y del imperio de la ley. En el presente artículo, el autor analiza el marco jurídico internacional, tanto de carácter convencional como de naturaleza consuetudinaria, que brinda protección a todas las personas que participan en las hostilidades y en cualquier otra forma de violencia regidas por el derecho internacional humanitario. En especial, se hace hincapié en aquellos actos vinculados a la violencia terrorista.
\end{abstract}

ABSTRACT: The relentless "Global War on Terrorism", headed by the United States after the events of 11-S of 2001, it has been a source of important negative consequences for the protection of the fundamental human rights. The approval or application of laws and antiterrorist politics apart from the legality and the Rule of Law in the international order promotes, also, the risk of betraying the justice reason and the supremacy of the law. In this paper, the author analyzes the conventional and customary international legal framework which provides protection to all the people that participate in the hostilities and in any other form of violence governed by the International Humanitarian Law. Especially, stressing those acts linked to the terrorist violence.

RÉSUMÉ: La “Guerre contre le Terrorisme”, présidé par les États-Unis après les actes des 11-S de 2001, il a eu des conséquences négatives importantes en se qui concernes la protection des Droits de l'Homme fondamentaux. L'approbation ou L'application de la loi et de la politique antiterroriste or de la légalité et de l'État de Droit dans l'ordre international encouragent, en outre, le risque de trahir la raison de la justice et la suprématie de la loi. Dans cet article, l'auteur analyse la structure légale internationale conventionnelle et coutumière qui fournit la protection à tous les gens qui participent aux hostilités ou sont lié a d'autres formes de violence réglée par le Droit International Humanitaire. Surtout, on va préciser spécialement les actes liés à la violence terroriste.

* Profesor de derecho internacional y relaciones internacionales de la Universidad de Sevilla. 
SUMARIO: I. Introducción. II. La protección internacional de las personas que participan en actos de violencia. III. El derecho de los conflictos armados. IV. El derecho internacional de los derechos humanos. V. Las personas que no gozan de un trato más favorable. VI. Conclusiones.

\section{INTRODUCCIÓN}

Los acontecimientos del 11-S de 2001 y sus secuelas, como la guerra mundial contra el terrorismo a que dieron lugar, las importantes consecuencias imprevistas para los derechos humanos y el riesgo de perjudicar la causa de la justicia y del imperio de la ley debido a la aprobación o aplicación de leyes y políticas antiterroristas al margen de la legalidad y del Estado de derecho a nivel internacional, ${ }^{1}$ han impulsado la creciente

1 Respecto al denominado Estado de derecho internacional o principio de Rule of Law, consideramos conveniente señalar que no existe actualmente dentro de la disciplina internacional una definición unánime en cuanto a su contenido, alcance e implicaciones. Esta afirmación puede constatarse al analizar la práctica internacional, tanto de los Estados como de las organizaciones internacionales y la propia jurisprudencia internacional. Sin embargo, y a pesar de la ausencia de un concepto generalmente aceptado en torno al Estado de derecho internacional, podríamos señalar que el mismo implicaría el funcionamiento de los órganos del sistema internacional de conformidad con los instrumentos que los rigen y con las normas de derecho internacional vigentes. Dentro del presente estudio no pretendemos realizar un análisis sobre la problemática que hasta hoy la indeterminación jurídico-conceptual del Estado de derecho ha originado a la luz del derecho internacional, ya que tal propósito excedería los límites materiales de estas páginas. En todo caso, y para un mayor abundamiento sobre el tema, véanse, entre otros: Carlson, S., "Establishing the Rule of Law", Georgia Journal of International and Comparative Law, vol. 33, 2004, pp. 119-141; Cassel, D., "The United States Supreme Court Rulings on Detention of Enemy Combatants: Partial Vindication of the Rule of Law", International Law Forum du droit international, vol. 6, 2004, pp. 122-125; Christenson, G., "World Civil Society and the International Rule of Law", Human Rights Quarterly, vol. 19, núm. 4, 1997, pp. 724-737; Douglas-Scott, S., "The Rule of Law in the European Union-Putting the security into the Area of Freedom, Security and Justice", European Law Review, vol. 29, núm. 2, 2004, pp. 219-242; Fletcher, B., "The Rule of Law, Terrorism and Countermeasures including the USA Patriot Act of 2001", Florida Journal of International Law, vol. 16, 2004, pp. 43-87; Heuschling, L., État de droit, Rechtsstaat, Rule of Law, París, Dalloz, 2002, p. 739; Morin, J. Y., "L'État de Droit: émergence d'un principe du Droit international", Recueil des Cours de l'Académie de Droit International, t. 254, 1995, pp. 13-462; Newman, G., "Comment, Counter-terrorism Operations and the Rule of Law", European Journal of International Law, vol. 15, 
atención que se presta, actualmente, a los efectos de las medidas antiterroristas en el disfrute de los derechos humanos.

Como es ampliamente conocido, tras los atentados del 11-S de 2001 perpetrados en el territorio de los Estados Unidos de América por parte de la organización terrorista Al Qaeda, el gobierno estadounidense, con el apoyo de una coalición de países entre los que se encontraban Francia, Alemania, Australia, Canadá y Gran Bretaña, inició, durante los primeros días de octubre de 2001, un ataque armado contra Afganistán.

A raíz de la intervención armada en Afganistán, cientos de personas han sido detenidas por la coalición internacional. Más de seiscientos individuos, de diversas nacionalidades, se encuentran, desde hace más de cuatro años, en la base naval de la bahía de Guantánamo, así como en otros lugares del mundo, ${ }^{2}$ sin cargos y sin haber gozado de un juicio previo, privados del acceso a los tribunales, de asistencia letrada, de comunicación con sus familiares ${ }^{3}$ y hasta hace muy poco en el anonimato. ${ }^{4}$

La actitud que desde el inicio del conflicto armado, surgido en tierras afganas, han adoptado las autoridades estadounidenses en el sentido de calificar a priori como terroristas y criminales a las personas detenidas en Guantánamo, considerándolas únicamente como combatientes ilegales y negándoles, en consecuencia, la protección prevista por el derecho in-

núm. 5, 2004, pp. 1019-1029; Pereira Menaut, C., Rule of Law o Estado de derecho, Madrid, Marcial Pons, 2003, p. 127.

2 Véase, por ejemplo, "CIA Holds Terror Suspects in Secret Prisons", Washington Post, 2 de noviembre de 2005, respecto a las prisiones secretas de la CIA en varios países del mundo, entre los cuales se encontrarían Tailandia, Afganistán, Polonia y Rumania, disponible en http://www.washingtonpost.com/wp-dyn/content/article/2005/11/01/AR200 5110101644.html., consultado el 3 de marzo de 2006.

3 Véase Amnistía Internacional, "Estados Unidos: excluidos de la protección de la ley", AI Index: AMR 51/184/2002, diciembre de 2002. En el mismo sentido, véase Amnistía Internacional, "Guantánamo: vidas desgarradas", AI Index: AMR 51/007/2006, febrero de 2006.

4 En fechas recientes (abril de 2006), el Departamento de Defensa de los Estados Unidos de América ha dado a conocer una lista con los nombres de 558 detenidos en la cárcel de la Bahía de Guantánamo. Esta información, impensable hasta ahora y que las autoridades estadounidenses se habían negado a facilitar alegando razones de seguridad nacional, ha sido posible gracias a la victoria de la agencia Associated Press en el juicio que entabló contra la administración estadounidense en aplicación de la Ley de Libertad de Información (FOIA, en sus siglas en inglés). La lista con los nombres y nacionalidad de los detenidos se encuentra disponible en http://www.defenselink.mil/pubs/foi/detainees/detainee_list.pdf, visitada el 20 de abril de 2006. 
ternacional humanitario y por el derecho internacional de los derechos humanos, ha sido duramente criticada por la gran mayoría de la comunidad internacional, que entiende que dichas personas cuentan con la protección que el derecho internacional ofrece a todas las personas que participan en un determinado acto de violencia. ${ }^{5}$

5 En este sentido, la opinión de la comunidad internacional de Estados en su conjunto estaría reflejada en las críticas efectuadas por diversos organismos internacionales, organizaciones no gubernamentales internacionales, así como por una gran cantidad de estudios doctrinales de autores de diversas nacionalidades, referentes a la actitud del gobierno de los Estados Unidos de América. Véanse, por ejemplo, Comisión Interamericana de Derechos Humanos, Detainees in Guantánamo Bay, Cuba: Request for Precautionary Measures, 12 de marzo de 2002, disponible en http://www. cidh.oas.org/medidas/2002.sp.htm, visitada el 12 de enero de 2006; Alto Comisionado de las Naciones Unidas para los Derechos Humanos, Statement of High Commissioner for Human Rights on Detention of Taliban and Al Qaida Prisioners at US Base in Guantánamo Bay, Cuba, 16 de enero de 2002, disponible en http://www.unhchr.ch/ huricane/huricane.nsf/newsroom, visitada el 16 de enero de 2006; Comité Internacional de la Cruz Roja, Geneva Convention on Prisioners of War, comunicado de prensa número 02/11, 9 de febrero de 2002, disponible en http://www.icrc.org/web/eng/sitespa0. nsf/iwpList74/8142D35C53CC34FEC1256DE10066C949, visitada el 20 de enero de 2006; Amnistía Internacional, Memorandum to the US Government on the rights of people in US custody in Afghanistan and Guantánamo Bay, abril de 2002, AI Index AMR 51/053/2002; Human Rights Watch, Background Paper on Geneva Conventions and Persons Held by US Forces, 29 de enero de 2002, disponible en http://www.hrw.org/back grounder/usa/pow-bck.htm, visitada el 20 de enero de 2006; Alcaide Fernández, J., "La lucha contra el terrorismo internacional a la luz del 11-S: de la zanahoria al palo", Agenda Internacional, Pontificia Universidad Católica del Perú, núm. 19, 2003, pp. 179-220; Aldrich, G., "The Taliban, Al Qaida and the Determination of Illegal Combatants", American Journal of International Law, vol. 96, 2002, pp. 891-898; Benavides, L., "El estatus jurídico internacional de los prisioneros detenidos por Estados Unidos de América en Guantánamo, Cuba, a raíz del conflicto en Afganistán", Anuario Mexicano de Derecho Internacional, México, UNAM, vol. III, 2003, pp. 67-91; Borelli, S., "Echar luz sobre un vacío jurídico: el derecho internacional y las detenciones en el extranjero en el marco de la 'guerra contra el terrorismo'", Revista Internacional de la Cruz Roja, núm. 857, 2005, pp. 39-68; Capellá I Roig, M., "El estatuto jurídico de Guantánamo (Cuba)", Revista Española de Derecho Internacional, vol. LIV, 2002, pp. 773-781; Chlopak, E., "Dealing with the detainees at Guantánamo Bay: Humanitarian and human rights obligations under the Geneva Conventions", Human Rights Brief, vol. 9, núm. 3, 2002, p. 1; Pérez González, J. L. y Rodríguez-Villasante y Prieto, J. L., "El caso de los detenidos en Guantánamo ante el derecho internacional humanitario y de los derechos humanos", Revista Española de Derecho Internacional, vol. LIV, núm. 1, 2002, pp. 11-39; Pozo Serrano, P., "El estatuto jurídico de las personas detenidas durante el conflicto armado internacional en Afganistán”, Anuario de Derecho Internacional, Universidad de 
En este sentido, y al margen de las numerosas transformaciones que los acontecimientos del 11-S de 2001 podrían haber introducido en el ámbito internacional, nuestra intención, con el presente estudio, es la de presentar algunas reflexiones relativas a la salvaguardia de los derechos humanos de aquellas personas que han sido detenidas en el contexto de una situación concreta de violencia. Por tal motivo, nos proponemos analizar el marco jurídico internacional que ampara a las personas que participan en un determinado acto de violencia, especialmente en cuanto a los actos de violencia terrorista se refiere.

De esta forma, partiendo de una concepción amplia del concepto "actos de violencia”, abordaremos el análisis de la situación de todas aquellas personas que tienen una implicación directa en dichos actos, tratando de dibujar un panorama de las normas que integrarían el marco jurídico internacional que les protege, tanto en su aspecto convencional como en su aspecto consuetudinario. Especialmente, analizaremos las disposiciones normativas que ampararían a las personas que, presuntamente, han participado en actos de violencia terrorista.

\section{LA PROTECCIÓN INTERNACIONAL DE LAS PERSONAS QUE PARTICIPAN EN ACTOS DE VIOLENCIA ${ }^{6}$}

El marco jurídico que regula la participación de las personas en los actos de violencia (entendida ésta desde una concepción amplia) estaría integrado, en un primer plano, por todas aquellas disposiciones conven-

Navarra, vol. XVIII, 2002, pp. 171-204; Sassóli, M., "La guerra contra el terrorismo, el derecho internacional humanitario y el estatuto de prisionero de guerra", Lecciones y Ensayos. Derecho Internacional Humanitario y Temas de Áreas Vinculadas, Universidad de Buenos Aires, núm. 78, 2003, pp. 549-583; Weckel, Ph., "Le statut incertaine des detenus sur la base américaine de Guantanamo", Revue Générale de Droit International, núm. 2, 2002, pp. 359-360.

6 Dentro del presente estudio, nos referiremos a las personas que intervienen en actos de violencia desde una perspectiva amplia del concepto. En este sentido, quedarán comprendidos dentro del término violencia todos aquellos actos que impliquen un determinado uso de la fuerza, independientemente de su intensidad y de la calificación que los mismos puedan tener a la luz del derecho interno o internacional. De esta forma, al hablar de actos de violencia, nos referiremos a aquellos actos que supongan un uso de la fuerza en general, y no al contexto en el cual puedan surgir, como pudiera ser, por ejemplo, un conflicto armado. De manera específica, aludiremos a los casos de terrorismo internacional. 
cionales que conforman tanto el derecho internacional humanitario como el derecho internacional de los derechos humanos $\mathrm{y}$, en un segundo plano, por todas aquellas disposiciones de naturaleza consuetudinaria, incluidos los principios generales del derecho internacional, que constituyen un estándar mínimo de protección respecto al, así denominado por el profesor Carrillo Salcedo, 7 "núcleo duro de los derechos humanos".

En razón de lo anterior, procederemos a explicar brevemente ambas vertientes, tanto la convencional como la consuetudinaria, a partir de las cuales se edificaría la protección internacional de las personas que participan en un determinado acto de violencia.

\section{El marco convencional}

Como anteriormente señalamos, una parte importante del marco jurídico internacional que rige la participación de las personas en los actos de violencia es de carácter convencional. Los Estados han concretado un gran número de tratados internacionales (obligatorios únicamente entre partes) que responden a la necesidad de proteger a las personas que, por cualquier motivo o circunstancia, se ven implicadas en una situación de violencia. Dichos tratados se encuentran comprendidos dentro de dos grandes disciplinas, que interactúan entre sí a la hora de brindar protección a los individuos, a saber: el derecho internacional humanitario y el derecho internacional de los derechos humanos.

En su aspecto convencional, los tratados pertenecientes al derecho internacional humanitario y al derecho internacional de los derechos humanos brindan una protección a las personas que participan en los actos de violencia, independientemente de que esa protección pueda derivar también de fundamentos extraconvencionales, es decir, de normas de derecho internacional consuetudinario o de principios generales del derecho internacional, situación que será analizada en el subapartado siguiente.

En este sentido, podemos apreciar que el marco jurídico que regula la participación de las personas en los actos de violencia, dentro de su aspecto convencional, estaría integrado por las normas contenidas en los tratados internacionales del derecho internacional humanitario y, con ca-

7 Carrillo Salcedo, J. A., Soberanía de los Estados y derechos humanos en derecho internacional contemporáneo, Madrid, Tecnos, 2001, p. 148. 
rácter supletorio, por determinadas disposiciones convencionales contenidas en los tratados relativos al derecho internacional de los derechos humanos, siempre y cuando dichas disposiciones no sean susceptibles de suspensión durante el transcurso de un conflicto armado, es decir, tengan carácter inderogable.

\section{El contenido consuetudinario}

Tal y como señalamos anteriormente, las normas consuetudinarias, así como los principios generales del derecho internacional, constituyen una parte elemental en la construcción de un marco jurídico que regule la participación de las personas en los actos de violencia.

Una proporción considerable de las normas que protegen a las personas implicadas en los actos de violencia es de orden consuetudinario. Muchas de ellas se encuentran plasmadas en los convenios internacionales que forman parte del derecho internacional humanitario y del derecho internacional de los derechos humanos. Asimismo, algunas de estas disposiciones constituyen verdaderos principios generales del derecho internacional, gozando, por lo tanto, de un carácter obligatorio para todos los Estados al margen de cualquier vínculo convencional. Así lo manifestó la Corte Internacional de Justicia en su opinión consultiva de 18 de mayo de 1951, relativa a la validez de ciertas reservas a la Convención para la Prevención y Sanción del Delito de Genocidio, al determinar que dicha convención contiene "principios reconocidos por las naciones civilizadas, obligatorios para todos los Estados incluso al margen de todo vínculo convencional". 8

Esta situación sería de capital importancia en cuanto a la protección de las personas afectadas por un acto de violencia, en el sentido de que, en su aspecto convencional, las normas insertas en los tratados o convenios internacionales habrían de ser aplicables, única y exclusivamente, entre los Estados que fueran parte en dicho instrumento, mientras que, por el contrario, la protección prevista en las normas consuetudinarias y los principios generales del derecho internacional sería obligatoria para todos los Estados, abstracción hecha de que fueran o no partes en el tratado internacional que pudiera ser aplicado en una concreta situación de violencia. 
La Corte Internacional de Justicia, en su sentencia de fecha 5 de febrero de 1970, en el asunto de la Barcelona Traction, ha determinado que los principios y las reglas relativos a los derechos fundamentales de la persona humana representan obligaciones de los Estados hacia la comunidad internacional en su conjunto, es decir, obligaciones erga omnes. ${ }^{9}$

En este sentido y en opinión del profesor Miaja de la Muela, ${ }^{10}$ la obligación de los Estados relativa a la protección de los derechos humanos de las personas que se encuentren bajo su jurisdicción derivaría de una obligación general impuesta por el derecho internacional, que tiene como beneficiaria a la comunidad internacional en su conjunto.

Al hilo de esta cuestión, debemos señalar que la misma Corte Internacional de Justicia, en su sentencia de 27 de junio de 1986, relativa al asunto de las Actividades Militares y Paramilitares en y contra Nicaragua, estableció que los Estados Unidos de América estaban obligados a respetar, e incluso a hacer respetar, las Convenciones de Ginebra de 1949 de derecho internacional humanitario, puesto que dicha obligación "no derivaba sólo de los convenios en sí, sino también de los principios generales del derecho humanitario de los que los convenios en cuestión no son más que la expresión concreta". ${ }^{11}$

Más recientemente, en la Opinión consultiva de 8 de julio de 1996, relativa a la Licitud de la Amenaza o el Empleo de Armas Nucleares, de nuevo la Corte Internacional de Justicia afirmaría que la comunidad internacional cuenta con un corpus de disposiciones contenidas en tratados que, en su mayoría, han cobrado carácter consuetudinario y que aparecen reflejadas en los principios humanitarios reconocidos a nivel universal y generalmente aceptados. ${ }^{12}$

Una vez que hemos presentado un panorama general sobre la integración del marco jurídico internacional que rige la participación de las personas en los actos de violencia, tanto en su aspecto convencional como consuetudinario, y siguiendo con la metodología planteada en el

9 CIJ, Recueil, 1970, parágrafo 31.

10 Miaja de la Muela, A., "Aportación de la sentencia del Tribunal de La Haya en el caso Barcelona Traction (5 de febrero de 1970) a la jurisprudencia internacional", Cuadernos de la Cátedra, Valladolid, J. B. Scott, 1970, p. 73.

11 ICJ, Reports, 1986, parágrafo 220.

12 Carrillo Salcedo, J. A., op. cit., nota 7, p. 145. 
inicio del presente estudio, pasaremos a efectuar un análisis específico de aquellas disposiciones normativas del derecho internacional humanitario.

\section{EL DERECHO DE LOS CONFLICTOS ARMADOS}

El derecho internacional humanitario, en palabras del profesor Benavides, es definido como:

Un conjunto de normas de carácter convencional o consuetudinario y de principios, tales como las consideraciones elementales de humanidad, necesidad de distinguir entre civiles y combatientes, principio de proporcionalidad, la prohibición de causar sufrimiento innecesario, entre otros, que por razones humanitarias trata de limitar los efectos de los conflictos armados. Protege a las personas que no toman parte en las hostilidades, como son los civiles y el personal médico y religioso. Protege asimismo a las personas que ya no participan en los combates, por ejemplo, los combatientes heridos o enfermos, los náufragos y los prisioneros de guerra. Asimismo, limita los medios y métodos de hacer la guerra. ${ }^{13}$

Como es conocido, el derecho internacional de los conflictos armados se encuentra esencialmente contenido en los cuatro Convenios de Ginebra de $1949^{14}$ y en sus dos protocolos adicionales de 1977. ${ }^{15}$ Respecto a estos últimos, es preciso señalar que muchos de los principios contenidos en ellos se consideran ya integrantes del derecho consuetudinario general y, por lo tanto, obligatorios para todos los países al margen de todo vínculo convencional. ${ }^{16}$

13 Benavides, L., op. cit., nota 5, p. 71.

14 I Convenio de Ginebra, de 12 de agosto de 1949, para Aliviar la Suerte que Corren los Heridos y los Enfermos de las Fuerzas Armadas en Campaña; II Convenio de Ginebra, de 12 de agosto de 1949, para Aliviar la Suerte que Corren los Heridos, los Enfermos y los Náufragos de las Fuerzas Armadas en el Mar; III Convenio de Ginebra, de 12 de agosto de 1949, relativo al Trato Debido a los Prisioneros de Guerra; III Convenio de Ginebra, de 12 de agosto de 1949, relativo a la Protección Debida a las Personas Civiles en Tiempo de Guerra.

15 I Protocolo Adicional a los Convenios de Ginebra, relativo a la Protección de las Víctimas de los Conflictos Armados Internacionales; II Protocolo Adicional a los Convenios de Ginebra relativo a la Protección de las Víctimas de los Conflictos Armados sin Carácter Internacional.

16 Así lo ha reconocido la Corte Internacional de Justicia en diversas ocasiones. Un ejemplo de dicha manifestación la encontramos en la sentencia de fecha 27 de junio de 
En este sentido, debe destacarse que una parte importante del derecho internacional humanitario es de carácter consuetudinario o se encuentra enunciada en los principios generales del derecho internacional. Tal es el caso, por ejemplo, de la cláusula Mártens. ${ }^{17}$ Esta disposición aparece recogida en el derecho internacional humanitario dentro de los artículos 63 del I Convenio de Ginebra, 62 del II Convenio de Ginebra, 142 del III Convenio de Ginebra, 158 del IV Convenio de Ginebra, y reafirmada en el artículo 1, párrafo segundo, del Protocolo Adicional I a dichos convenios. ${ }^{18}$

Al respecto, la Corte Internacional de Justicia, en su Opinión consultiva de 8 de julio de 1996, relativa a la Licitud de la Amenaza o el Empleo de Armas Nucleares, ha manifestado que existen una serie de principios cardinales que constituyen la base del derecho internacional humanitario, a saber: el principio de distinción, la prohibición de usar armas de efecto indiscriminado, la prohibición de causar sufrimientos innecesarios a los combatientes y el hecho de que no es ilimitado el derecho de los Estados a elegir medios de hacer la guerra. ${ }^{19}$ Estos principios cardinales constituirían la esencia del derecho internacional que rige las si-

1986, relativa al Asunto de las Actividades Militares y Paramilitares en y contra Nicaragua, en la que la corte estableció que la obligación de los Estados de respetar, e incluso hacer respetar, las convenciones de derecho internacional humanitario, "no resulta sólo de las convenciones en sí, sino también de los principios generales del derecho internacional humanitario de los que las convenciones no son más que la expresión concreta" (ICJ, op. cit., nota 11). Por otra parte, y continuando con esta misma argumentación, en la opinión consultiva de fecha 8 de julio de 1996, relativa a la Licitud de la Amenaza o del Uso de las Armas Nucleares, el máximo órgano jurisdiccional expresó, al referirse a los principios del derecho internacional humanitario, que: "estas normas fundamentales deben ser observadas por todos los Estados, hayan o no ratificado los instrumentos convencionales que los contienen, porque constituyen principios inquebrantables del derecho internacional consuetudinario" (ICJ, Reports, 1996, parágrafo 79).

17 Como es sabido, la Cláusula Mártens forma parte del derecho de los conflictos armados desde que apareciera, por primera vez, en el preámbulo del II Convenio de La Haya de 1899, relativo a las leyes y costumbres de la guerra terrestre. Sobre el tema véase, entre otros, Meron, T. H., "The Martens Clause, Principles of Humanity, and Dictates of Public Conscience", American Journal of International Law, vol. 94, 2000, pp. 78 y ss.

18 Doménech Omedas, J. L., "Los sujetos combatientes", en Rodríguez Villasante y Prieto, J. L. (coord.), Derecho Internacional Humanitario, Valencia, Tirant Lo Blanch, 2002, p. 163.

19 ICJ, op. cit., nota 16, parágrafo 78. 
tuaciones de conflicto armado. A partir de ellos, estaría edificado todo el conjunto de normas que integran el denominado derecho internacional humanitario. ${ }^{20}$

A la luz de este conjunto normativo, de carácter convencional y general, aquellas personas que se encuentren en poder de una parte enemiga, con motivo de un conflicto armado, están amparadas por las normas del derecho internacional humanitario o, en su defecto, por todas aquellas normas que formen parte del derecho consuetudinario internacional.

\section{El concepto de combatiente}

En conflictos armados internacionales, el término "combatientes" se refiere a las personas que tienen derecho a un régimen especial para participar directamente en las hostilidades. ${ }^{21}$ El concepto de combatiente encierra dos cuestiones esenciales:

En primer lugar, otorga dos derechos fundamentales, de los cuales derivan todos los demás: a) El poder participar directamente en las hostilidades, según especifica el artículo 43 del Protocolo Adicional I de 1977,22 sin que tales actos sean delito ni pueda haber persecución por ello, y b) El derecho a ser tratado como prisionero de guerra en el su-

20 Para un estudio detallado sobre la práctica reciente de los Estados en cuanto a los principios que integran la esencia del derecho internacional humanitario, véase Henckaerts, J. M. y Doswald-Beck, L., Customary International Humanitarian Law, vol. I: Rules y vol. II: Practice (partes 1 y 2), Cambridge, Cambridge University Press, 2005, p. 411.

21 Véase el artículo 43 del Protocolo Adicional I a los Convenios de Ginebra de 1949, relativo a la Protección de las Víctimas de los Conflictos Armados Internacionales.

22 El artículo 43 del Protocolo Adicional I de Ginebra de 1977, especifica: "1. Las fuerzas armadas de una parte en conflicto se componen de todas las fuerzas, grupos y unidades armados y organizados, colocados bajo un mando responsable de la conducta de sus subordinados ante esa parte, aun cuando ésta esté representada por un gobierno o por una autoridad no reconocidos por una parte adversa. Tales fuerzas armadas deberán estar sometidas a un régimen de disciplina interna que haga cumplir, inter alia, las normas de derecho internacional aplicables en los conflictos armados. 2. Los miembros de las fuerzas armadas de una parte en conflicto (salvo aquellos que formen parte del personal sanitario y religioso a que se refiere el artículo 33 del III convenio) son combatientes, es decir, tienen derecho a participar directamente en las hostilidades. 3. Siempre que una parte en conflicto incorpore a sus fuerzas armadas un organismo paramilitar o un servicio armado encargado de velar por el orden público, deberá notificarlo a las otras partes en conflicto". 
puesto de caer en poder del enemigo y recibir, asimismo, la protección y cuidado debido a los heridos, enfermos y náufragos de las fuerzas armadas.

En segundo lugar, impone dos deberes esenciales de los cuales se desprenden los demás: a) El de no poder utilizar armas ni medios prohibidos en las leyes y usos de guerra, y $b$ ) El de tratar al enemigo en su poder con arreglo a las normas de la guerra y, en particular, a las del derecho internacional humanitario. ${ }^{23}$

Por consiguiente, los combatientes no pueden ser enjuiciados por actos lícitos de guerra cometidos en el transcurso de las operaciones militares, aunque su comportamiento constituya un crimen grave en tiempo de paz. Sólo pueden ser enjuiciados por violaciones del derecho internacional humanitario, ${ }^{24}$ en particular por los crímenes de guerra. Además, cuando son capturados, los combatientes tienen derecho a recibir el estatuto de prisionero de guerra y a gozar de la protección que les proporciona el III Convenio de Ginebra.

El estatuto de prisionero de guerra, como prerrogativa inherente a los combatientes y los derechos que con su reconocimiento se originan, será objeto de análisis en el siguiente apartado.

\section{El estatus del prisionero de guerra}

Por regla general, el estatuto de prisionero de guerra constituye un derecho inherente a los combatientes dentro de un conflicto armado, desde el momento en que caen en poder del enemigo hasta su repatriación definitiva.

Las condiciones para obtener el estatuto de combatiente y, por lo tanto, el de prisionero de guerra, figuran en el artículo 4 del III Convenio de Ginebra, así como en los artículos 43 y 44 del Protocolo Adicional I, que amplían el mencionado artículo 4.

Al respecto, encontramos que el artículo 4 del III Convenio de Ginebra, de 1949, menciona que son prisioneros de guerra las personas que, perteneciendo a una de las siguientes categorías, caigan en poder del enemigo:

23 Fernández Flores, J. L., Del derecho de la guerra, Madrid, Ediciones del Ejército, p. 255.

24 Garner, J. W., "Punishment of offenders against the laws and customs of war", American Journal of International Law, vol. 14, 1920, p. 70. 
[1.] Los miembros de las fuerzas armadas de una parte en conflicto...

[2.] Miembros de los movimientos de resistencia organizados, milicias y cuerpos de voluntarios no pertenecientes a las fuerzas armadas de una parte en conflicto...

[3.] Los miembros de las fuerzas armadas regulares que sigan instrucciones de un gobierno o autoridad no reconocidos por la potencia detentadora...

[4.] Las personas que sigan a las fuerzas armadas sin formar parte integrante de ellas...

[5.] Los miembros de las tripulaciones de la marina mercante y de la aviación civil que no resulten más protegidos por otras disposiciones... ${ }^{25}$

[6.] Las personas de un territorio no ocupado que, al acercarse el enemigo, tomen espontáneamente las armas sin haberse constituido en fuerzas armadas regulares, por falta de tiempo, si llevan las armas a la vista y respeten las normas y costumbres de guerra.

Además de las categorías descritas, se beneficiarán del trato de prisionero de guerra, de acuerdo con lo establecido por el inciso b) del mismo artículo 4 del III Convenio de Ginebra de 1949, las personas pertenecientes a las fuerzas armadas de un territorio ocupado y las personas pertenecientes a alguno de las categorías citadas que, recibidas en un territorio neutral o no beligerante, éstos tengan la obligación de internar en virtud del derecho internacional, sin perjuicio de un trato más favorable.

Una vez que las personas cumplen con los requisitos para ser consideradas combatientes, tienen derecho a que se les atribuya el estatuto de prisionero de guerra. Dicho estatus jurídico proporciona a los individuos que lo poseen determinados derechos y beneficios.

De este modo, el III Convenio de Ginebra de 1949 establece ciertos principios rectores que inspiran toda la regulación posterior y detallada del trato a los prisioneros de guerra. Estos principios derivados podrían resumirse así:

a) El prisionero de guerra debe ser tratado siempre con humanidad. Queda prohibida la tortura. ${ }^{26}$

25 Pictet, J., Commentaire III La Convention de Géneve relative au traitement des prisonniers de guerre, Comité Internacional de la Cruz Roja, 1958, p. 75.

26 Véase III Convenio de Ginebra de 1949, artículo 13. 
b) El prisionero de guerra tiene derecho pleno a su dignidad personal y a su honor. ${ }^{27}$

c) El prisionero de guerra tiene derecho a ser mantenido sin tener que pagar manutención. ${ }^{28}$

d) El prisionero de guerra tiene derecho a un trato igual y sin discriminación con respecto a los demás prisioneros de guerra. ${ }^{29}$

Por otra parte, y dentro de la materia procesal, podríamos señalar que las garantías judiciales de los prisioneros de guerra previstas en el derecho internacional humanitario corresponderían, a grandes rasgos, con las garantías que figuran en los documentos universales o regionales de protección de los derechos humanos. Sin embargo, en ciertas circunstancias, algunas de estas garantías (en materia de derechos humanos) podrían suspenderse si existiere un peligro público excepcional que amenazase la existencia de la nación. Las garantías judiciales previstas por el derecho internacional humanitario son, por el contrario, irrevocables. Así ha quedado establecido por el artículo 7 del III Convenio de Ginebra de 1949.

De manera particular, y al margen de las garantías judiciales contenidas en el III Convenio de Ginebra, debemos mencionar que es, precisamente, dentro de los protocolos adicionales donde podemos encontrar con mayor claridad todo un catálogo de garantías judiciales a favor de los prisioneros de guerra.

En este sentido, podemos ver que, a la luz de los protocolos adicionales a los Convenios de Ginebra de 1949, toda aquella persona que se encuentre en poder de una parte en conflicto gozará de una serie de derechos que podrían resumirse en las siguientes cuatro ideas:

El derecho a la presunción de inocencia, que se encuentra regulado por los artículos 75, apartado 4, inciso "d", del Protocolo Adicional I y 6, apartado 2, inciso "d", del Protocolo Adicional II.

El derecho a encontrarse presente al ser juzgado, que aparece establecido en los artículos 75, apartado 4, inciso "e", del Protocolo Adicional I y 6, apartado 2, inciso "e", del Protocolo Adicional II. 
El derecho a no declarar contra sí mismo ni a confesarse culpable, reconocido por los artículos 75, apartado 4, inciso "f", del Protocolo Adicional I y 6, apartado 2, inciso " $\mathrm{f}$ ", del Protocolo Adicional II.

El derecho a que la sentencia sea pronunciada públicamente, que viene encuadrado en el artículo 75, apartado 4, inciso "i", del Protocolo Adicional I.

Como hemos venido señalando, las disposiciones normativas de los protocolos adicionales a las Convenciones de Ginebra de 1949 no tienen la vocación universal que, por el contrario, sí sería predicable de los cuatro Convenios de Ginebra. Los protocolos adicionales no han sido ratificados por un gran número de países..$^{30}$ No obstante, algunas de sus disposiciones son obligatorias para cualquier Estado, al margen de todo vínculo convencional, ya que están inspiradas, como se vio, en las consideraciones elementales de humanidad a las que se había referido la Corte Internacional de Justicia en su sentencia de 9 de abril de 1949, relativa al asunto del Estrecho de Corfú. ${ }^{31}$ Particularmente, habría que referirse al artículo 75 del Protocolo Adicional I que, bajo el título de "garantías fundamentales", prescribe las normas mínimas de trato humano para personas que están en poder de una parte en un conflicto armado internacional y no gozan de un trato más favorable en virtud de los Convenios de Ginebra o del propio Protocolo Adicional I y que, en palabras del profesor Jean Pictet, constituye el más completo código de garantías judiciales. ${ }^{32}$

En virtud de todo lo argumentado hasta ahora, podríamos afirmar que el hecho de asignar el estatuto de prisionero de guerra a una persona capturada por una potencia enemiga modifica radicalmente tanto su condición jurídica como el trato que tiene derecho a recibir. ${ }^{33}$ En relación con lo anterior, podríamos cuestionarnos qué sucedería en el caso de que surgieran dudas a la hora de conceder el estatuto de prisionero de guerra a una persona que, tras haber cometido un acto de beligerancia, cayera en poder del enemigo.

30 Hasta marzo de 2006, 151 Estados han ratificado el Protocolo Adicional I a los Convenios de Ginebra, y 97 Estados han ratificado el Protocolo Adicional II a los Convenios de Ginebra.

31 CIJ, Recueil, 1949, parágrafo 29.

32 Pictet, J., Desarrollo y principios del derecho internacional humanitario, Ginebra, Instituto Henry Dunant, 1986, p. 80.

33 Naqvi, Y., "Doubtful prisoner of war status", Revista Internacional de la Cruz Roja, núm. 847, 2002, p. 571. 
En nuestro caso particular, y tomando en cuenta la actitud de las autoridades estadounidenses en relación con las personas detenidas en la base militar estadounidense de Guantánamo, consideramos elemental determinar cuál sería el procedimiento que prevén las disposiciones legales del derecho de los conflictos armados a la hora de resolver las dudas existentes respecto de la calificación de los cautivos como prisioneros de guerra.

En este sentido, encontramos que el artículo 5 del III Convenio de Ginebra establece la regla aplicable a los casos de duda, al mencionar en su párrafo segundo que:

De haber duda respecto a la pertenencia a una de las categorías enumeradas en el artículo 4, de las personas que hayan cometido actos de beligerancia y que hayan caído en manos del enemigo, las dichas personas gozarán de la protección del presente convenio, en espera de que su estatuto haya sido determinado por un tribunal competente.

Esta disposición establece que el estatus jurídico de los cautivos deberá ser determinado mediante un procedimiento formal. Al respecto, convendría adelantar que la determinación del estatuto de los prisioneros de guerra no depende de la voluntad de la potencia en cuyo poder se encuentren las personas detenidas; por el contrario, se establece la obligación de iniciar un procedimiento formal, en el cual un tribunal competente, que ofrezca las garantías esenciales de independencia e imparcialidad generalmente reconocidas, determinará si las personas tienen derecho o no a recibir el estatuto de prisionero de guerra.

A la luz del artículo 5, segundo párrafo, del III Convenio de Ginebra, la aplicación del estatuto de prisionero de guerra a una persona que haya cometido un acto de beligerancia podría quedar en tela de juicio, únicamente, cuando existieran serias dudas respecto de su pertenencia a una de las categorías de combatientes del artículo 4 del III Convenio de Ginebra, o bien cuando a la persona capturada se le negara ese estatuto pero manifestara tener derecho a beneficiarse de él. ${ }^{34}$

Por otra parte, y a pesar de que dicho artículo no hace referencia expresa a las garantías judiciales que habrían de concedérseles a las personas que comparecieran ante este tribunal competente, sería conveniente 
recordar que las normas básicas de los derechos humanos que garantizan el derecho a un proceso que ofrezca las debidas garantías, podrían resultar aplicables. ${ }^{35}$ Por si ello no fuera suficiente, dentro del derecho internacional humanitario, los derechos fundamentales al proceso con las debidas garantías, están incluidos también en el artículo 75 del Protocolo Adicional I, ${ }^{36}$ así como en el artículo 3 común a los Convenios de Ginebra, ${ }^{37}$ los cuales forman parte del derecho internacional consuetudinario.

En este sentido, podríamos afirmar que, cuando las personas están bajo la autoridad y control de un Estado con motivo de un conflicto armado, sus derechos fundamentales pueden determinarse tanto por referencia al derecho internacional humanitario como al derecho internacional de los derechos humanos. Como ha señalado recientemente el relator especial de la Comisión de Derechos Humanos, Leandro Despouy, en su informe titulado Los Derechos Civiles y Políticos, en Particular las Cuestiones Relacionadas con la Independencia del Poder Judicial, la Administración de Justicia y la Impunidad, el principio que guía la relación entre el derecho internacional de los derechos humanos y el derecho interna-

$35 C f r$., por ejemplo, Conjunto de principios para la protección de todas las personas sometidas a cualquier forma de detención o prisión (resolución de la Asamblea General de Naciones Unidas número 43/173, de 9 de diciembre de 1988); artículos 9 y 14 del Pacto Internacional de Derechos Civiles y Políticos (resolución de la Asamblea General de Naciones Unidas número 2200 A (XXI), de 16 de diciembre de 1966); artículos 6-11 de la Declaración Universal de Derechos Humanos (resolución de la Asamblea General de Naciones Unidas número 217 A (III), de 10 de diciembre de 1948); artículos II, XVIII, XXV y XXVI de la Declaración Americana de Derechos y Deberes del Hombre de 1948, y Reglas Mínimas para el Tratamiento de los Reclusos, resolución de la Asamblea General de Naciones Unidas número 43/173, de 9 de diciembre de 1988.

36 Véase, en particular, el artículo 75, apartado tercero, que establece: "Toda persona detenida, presa o internada por actos relacionados con el conflicto armado será informada sin demora, en un idioma que comprenda, de las razones que han motivado esas medidas. Salvo en los casos de detención o prisión por una infracción penal, esa persona será liberada lo antes posible y en todo caso en cuanto desaparezcan las circunstancias que hayan justificado la detención, la prisión o el internamiento". Cfr. también el artículo 75, apartado cuarto, en el que se enuncian los derechos fundamentales a un procedimiento ordinario.

37 Véase, específicamente, el artículo 3 común a los cuatro Convenios de Ginebra, en su apartado primero, inciso "d", en el cual prohíbe, en todo tiempo y lugar: "las condenas dictadas y las ejecuciones sin previo juicio ante un tribunal legítimamente constituido, con garantías judiciales reconocidas como indispensables por los pueblos civilizados". 
cional humanitario no es el de exclusión o incompatibilidad sino el de armonización y complementariedad. ${ }^{38}$

Por último, y recordando lo manifestado dentro de este apartado en el sentido de que, en algunos casos, los derechos fundamentales de las personas que participan en los conflictos armados podrían quedar determinados mediante la aplicación supletoria del derecho internacional de los derechos humanos, consideramos importante analizar el contenido y alcance de este sector del ordenamiento internacional, labor a la que se dedicará el apartado siguiente del presente estudio.

\section{EL DERECHO INTERNACIONAL DE LOS DERECHOS HUMANOS}

De acuerdo con el profesor Fernández de Casadevante Romani, podríamos definir al derecho internacional de los derechos humanos como aquel sector del ordenamiento internacional, compuesto por normas de naturaleza convencional, consuetudinaria e institucional, que tiene por objeto la protección de los derechos y libertades fundamentales del ser humano inherentes a su dignidad. ${ }^{39}$

Para este autor, el derecho internacional de los derechos humanos además de representar un sector reciente del derecho internacional, está caracterizado por el papel predominante del Estado en la medida en que, tratándose de los mecanismos convencionales, las técnicas de control consistentes en las denuncias - bien entre Estados, bien de un particular a un Estado - se encuentran condicionadas a la previa aceptación por el Estado concernido de la competencia del órgano internacional que contemple el tratado en cuestión. A pesar de la posición predominante del Estado cabe constatar un fortalecimiento de este sector del derecho internacional. De un lado, por la progresiva aceptación de tales técnicas por los Estados. De otro, por los avances producidos en materia de la respon-

38 Parágrafo núm. 34 del Informe del Relator Especial sobre la Independencia de los Magistrados y Abogados, Comisión de Derechos Humanos, 20 de enero de 2005, documento E/CN.4/2005/60.

39 Fernández de Casadevante Romani, C., "El derecho internacional de los derechos humanos", en id. (coord.), Derecho internacional de los derechos humanos, Madrid, Dilex, 2003, p. 61. 
sabilidad penal individual de la persona, ${ }^{40}$ con independencia de que ésta haya cometido las violaciones de los derechos humanos en el ejercicio o no de sus funciones públicas. ${ }^{41}$

En este sentido, y toda vez que los derechos fundamentales de las personas que participan en los actos de violencia, en algunas circunstancias podrían determinarse con base en la aplicación supletoria de las normas del derecho internacional de los derechos humanos, consideramos pertinente efectuar, a continuación, un análisis de aquellas garantías civiles contenidas en los tratados de derechos humanos que integran el derecho internacional de los derechos humanos.

\section{Las garantías inderogables que emanan de los textos internacionales relativos a los derechos humanos}

Las garantías civiles reconocidas por el derecho internacional de los derechos humanos se encuentran esencialmente enunciadas, por un lado, en los instrumentos internacionales que constituyen la que se conoce como Carta Internacional de los Derechos Humanos, con vocación universal, integrada por la Declaración Universal de los Derechos Humanos, el Pacto Internacional de los Derechos Económicos, Sociales y Culturales, el Pacto Internacional de Derechos Civiles y Políticos y sus dos protocolos facultativos, ${ }^{42}$ y por otro, en los diversos convenios regionales de protección de los derechos humanos.

Estas normas, en un principio, serían aplicables en todo momento y lugar. A pesar de ello, algunas de las mismas pueden ser suspendidas en situaciones excepcionales que pongan en peligro la vida de la nación, específicamente en casos de conflicto armado. ${ }^{43}$

40 Para un estudio mas detallado al respecto, véase Greppi, E., "La evolución de la responsabilidad penal individual bajo el derecho internacional", Revista Internacional de la Cruz Roja, núm. 835, 1999, pp. 531-554.

41 Sobre el tema, véase Bassiouni, C., Derecho penal internacional, Proyecto de código penal internacional, trad. de José Luis de la Cuesta Arzamendi, Madrid, Tecnos, 1984, pp. 45 y ss.

42 Carrillo Salcedo, J. A., op. cit., nota 7, p. 57.

43 Dicha cláusula podemos encontrarla en el artículo 4 del Pacto Internacional de Derechos Civiles y Políticos, en el artículo 15 del Convenio Europeo de Derechos Humanos y en el artículo 27 de la Convención Americana sobre Derechos Humanos. 
Sin embargo, en contrapartida a estas garantías derogables en situaciones excepcionales, existe un mínimo de derechos básicos que no pueden ser suspendidos bajo ninguna circunstancia, ni siquiera durante el transcurso de un conflicto armado, en razón de que estos derechos representan un mínimo jurídico basado en las consideraciones elementales de humanidad y de que, a su vez, son parte integrante del anteriormente señalado núcleo duro de los derechos humanos. Estas garantías irreductibles están reconocidas por el artículo 4 del Pacto Internacional de Derechos Civiles y Políticos, por el artículo 15 del Convenio Europeo de Derechos Humanos y por el artículo 27 de la Convención Americana sobre Derechos Humanos.

Serían precisamente esta serie de garantías inderogables las que servirían de aplicación supletoria a la hora de determinar los derechos de las personas que participan en los actos de violencia, en el sentido de que las mismas no pueden suspenderse ni aún durante el transcurso de un conflicto armado. Es decir, no todos los derechos reconocidos en los instrumentos internacionales que integran el derecho internacional de los derechos humanos podrían aplicarse de manera supletoria al derecho internacional humanitario, sino solamente aquellos derechos inderogables que integran el núcleo duro de los derechos humanos. ${ }^{44}$

La función de complementación e interacción entre el derecho internacional humanitario y el derecho internacional de los derechos humanos, a la hora de proteger a las personas que participan en los actos de violencia, será objeto de análisis en el apartado siguiente.

\section{Interacción del derecho internacional de los derechos humanos y el derecho de los conflictos armados}

El derecho internacional humanitario y el derecho internacional de los derechos humanos tienen un objetivo común: la protección de la persona humana y el respeto de su dignidad. No obstante, estas dos ramas del derecho internacional público son de índole y de origen distintos, y han evolucionado de diferente forma.

44 Para un estudio en profundidad respecto al multicitado "núcleo duro de los derechos humanos", véase, por ejemplo, Marzal, A. (coord.), El núcleo duro de los derechos humanos, Barcelona, Bosch, 2001, p. 237. 
Sin embargo, los cambios ocurridos en el mundo desde la Segunda Guerra Mundial, la irresistible escalada, estos últimos decenios, de la violencia y de la miseria y, en consecuencia, la necesidad de garantizar una mejor protección a las víctimas de las violaciones de los derechos fundamentales de la persona humana, han relativizado los ámbitos tradicionales de aplicación material del derecho internacional humanitario y de los derechos humanos, contribuyendo, así, no sólo al desarrollo sino también al acercamiento paulatino de ambos sistemas.

En este sentido, el derecho internacional humanitario comenzaría a penetrar en el ámbito de aplicación tradicional del derecho internacional de los derechos humanos, en virtud de que, por ejemplo, el artículo 3 común a los Convenios de Ginebra impuso a las partes la obligación de respetar, en caso de un conflicto armado ya sea o no internacional, determinadas reglas mínimas de humanidad en favor de las personas, regulando así las relaciones entre el Estado y los individuos.

A su vez, el derecho internacional de los derechos humanos comenzaría a penetrar, igualmente, en el ámbito tradicional de aplicación del derecho internacional humanitario, en el sentido de que los tratados y convenios sobre derechos humanos establecerían una serie determinada de derechos inderogables que deben ser respetados incluso en caso de conflicto armado. De esta forma, la protección de ciertos derechos humanos fundamentales se garantiza no sólo en tiempo de paz, sino también en tiempo de guerra.

En cuanto a la coincidencia en los derechos protegidos, el derecho internacional humanitario y el derecho internacional de los derechos humanos comparten el denominado "núcleo duro" de los derechos fundamentales de la persona humana. La prohibición de suspender o derogar las garantías que emanan de este núcleo duro de los derechos humanos está vigente tanto en tiempo de paz como en tiempo de guerra.

Al respecto, cabría señalar que, más que una coincidencia en cuanto al contenido de estos derechos, existe una complementariedad entre el derecho internacional humanitario y el derecho internacional de los derechos humanos. Dicha complementariedad estaría determinada, en primer lugar, por la prohibición, inserta en los instrumentos de derechos humanos, de que las medidas que suspendan o deroguen sus derechos sean incompatibles con las demás obligaciones que impone el derecho internacional; en segundo lugar, por el mandato del artículo 3 común de que las 
personas sean, en todas las circunstancias, tratadas con humanidad, propósito básico del derecho internacional humanitario. ${ }^{45}$

Para el profesor Alcaide Fernández, este núcleo inderogable de derechos, o "núcleo duro", que ambos sistemas jurídicos reconocen, representa la mejor y principal consecuencia de la interacción entre el derecho internacional humanitario y el derecho internacional de los derechos humanos. ${ }^{46}$

Para nuestro objeto de estudio resulta particularmente relevante analizar la protección que el derecho internacional debe otorgar a aquellas personas que, con motivo de un conflicto armado, se encuentren en poder de una parte enemiga, específicamente la situación de los combatientes ilegales o no privilegiados y la de los terroristas. A esta labor estará dedicado el apartado siguiente del presente trabajo.

\section{LAS PERSONAS QUE NO GOZAN DE UN TRATO MÁS FAVORABLE}

Como hemos visto, para obtener la condición de persona protegida a la luz de los Convenios de Ginebra de 1949, los individuos deben cumplir con una serie de requisitos que las normas insertas en dichos instrumentos contemplan. ${ }^{47}$

Cuando hacemos referencia a los individuos que no gozan de un trato más favorable, esencialmente, queremos indicar que aquellos que no hayan reunido los requisitos para ser considerados personas protegidas por alguno de los Convenios de Ginebra (como podría ser el caso de los llamados combatientes ilegales y los terroristas), no tendrán derecho a beneficiarse de ese sistema específico y pormenorizado de protección que dichos instrumentos internacionales establecen, el cual, por sí mismo, constituye precisamente un trato más favorable respecto a ese estándar mínimo de seguridad emanado del "núcleo duro" de los derechos hu-

45 Alcaide Fernández, J., "La interacción entre el derecho internacional humanitario y el derecho internacional de los derechos humanos", Cuadernos de Derecho, Sevilla, UNED-Centro Asociado de Sevilla, núm. 3, 1990, p. 27.

46 Ibidem, p. 12.

47 Véanse los artículos siguientes: 13 del I Convenio de Ginebra; 13 del II Convenio de Ginebra; 4 del III Convenio de Ginebra y 4 del IV Convenio de Ginebra. En ellos se establecen las condiciones bajo las cuales cada individuo podrá ser considerado persona protegida por las disposiciones legales contenidas en cada uno de los mencionados convenios. 
manos que protege a los individuos que no entran en el ámbito de aplicación personal de alguno de los convenios de Ginebra de 1949.

Por nuestra parte, y por cuestiones metodológicas, analizaremos, en el apartado siguiente, la figura de los combatientes ilegales o no privilegiados y las normas aplicables para los casos de terrorismo internacional.

\section{Los combatientes ilegales o no privilegiados}

El tema de los combatientes ilegales o no privilegiados se ha convertido últimamente, a raíz sobre todo de la intervención armada que Estados Unidos de América efectuó en Afganistán tras los atentados terroristas del 11-S de 2001, en una cuestión ampliamente comentada y debatida. ${ }^{48}$

En este sentido, podemos apreciar que, mientras que los términos "combatiente", "prisionero de guerra" y "persona civil" se emplean y definen generalmente en los tratados del derecho internacional humanitario, el de "combatiente ilegal o no privilegiado" no figura en ellos. Sin embargo, se ha utilizado con frecuencia, al menos desde el comienzo del último siglo, en textos jurídicos, en manuales militares y en la jurisprudencia. ${ }^{49}$

Por nuestra parte, bajo la expresión "combatientes ilegales" abarcaremos a todas las personas que participan directamente en las hostilidades sin estar autorizadas a hacerlo, y que por ello no pueden ser conside-

48 Sobre esta cuestión, véanse Aldrich, G., op. cit., nota 5, pp. 891 y ss.; Alto Comisionado de la Naciones Unidas para los Derechos Humanos, op. cit., nota 5; Amnistía Internacional, United States of America. Memorandum to the US Government on the rights of people in US custody in Afghanistan and Guantánamo Bay, AI Index: AMR 51/053/2002, abril de 2002; Benavides, L., op. cit., nota 5, pp. 67 y ss.; Chlopak, E., op. cit., nota 5, pp. 6 y ss.; Comisión Interamericana de Derechos Humanos, op. cit., nota 5; Dormann, K., "La situación jurídica de los combatientes ilegales/no privilegiados", Revista Internacional de la Cruz Roja, núm. 849, 2003, pp. 45 y ss.; Human Rights Watch, op. cit., nota 5; Naqvi, Y., op. cit., nota 33, pp. 571 y ss.; Pérez González, J. L. y Rodríguez-Villasante y Prieto, J. L., op. cit., nota 5, pp. 11 y ss.; Pozo Serrano, P., op. cit., nota 5, pp. 171 y ss.; Weckel, Ph., op. cit., nota 5, pp. 359 y ss.

49 Para mayor abundamiento al respecto, véase Dormann, K., op. cit., nota anterior, p. 46. 
radas como prisioneros de guerra en el caso de caer en poder del enemigo. Esta es la interpretación más comúnmente aceptada. ${ }^{50}$

En cuanto a las normas que serían aplicables a esta categoría de personas, en el momento de determinar la protección que el derecho internacional les concede, en un primer plano, habría que determinar si los mismos entran en el ámbito de aplicación personal del IV Convenio de Ginebra.

En cuanto al ámbito de aplicación personal del IV Convenio de Ginebra, su artículo 4 señala que: "El presente convenio protege a las personas que, en cualquier momento y de la manera que sea, estén, en caso de conflicto o de ocupación, en poder de una parte en conflicto o de una potencia ocupante de la cual no sean súbditas".

De conformidad con el párrafo anterior, parecería que toda persona que caiga en poder de una parte en conflicto o de una potencia ocupante estaría protegida por el IV Convenio de Ginebra, es decir, tendría la calidad de civil protegido. Sin embargo, esto no sería así en la práctica, toda vez que para que este convenio proteja a alguna persona considerada como combatiente ilegal, tendría que cumplir con el requisito de la nacionalidad, esto es, no ser nacional de la parte o potencia en cuyo poder se encuentre.

Sin embargo, aún en el caso de que la persona considerada combatiente ilegal no cumpliese con el requisito estipulado por el artículo 4 del IV convenio para tener la calidad de civil protegido, difícilmente se podría sostener que los combatientes ilegales no tendrían derecho a protección alguna en virtud del derecho internacional humanitario. Si reúnen los requisitos de nacionalidad estipulados en el artículo 4 del IV Convenio de Ginebra estarán, sin lugar a dudas, protegidos por ese convenio; si, por el contrario, no los reúnen, contarán con el amparo de las garantías previstas en el artículo 75 del Protocolo Adicional I, sin perjuicio de la protección que, en virtud de las normas del derecho internacional consuetudinario, les corresponda. Efectivamente, nadie en poder del enemigo está fuera de la ley.

Ahora bien, como hemos visto, dentro de la categoría de combatientes ilegales quedarían comprendidas todas aquellas personas que no tie-

50 Al respecto, véanse, entre otros: Aldrich, G., op. cit., nota 5, p. 892; Comisión Interamericana de Derechos Humanos, Informe sobre Terrorismo y Derechos Humanos, OEA/Ser.L/V/II.116 Doc. 5 rev. 1, 22 de octubre de 2002, parágrafo 69. 
nen la legitimación necesaria para intervenir, conforme a derecho, en las hostilidades. Es, precisamente, dentro de esta categoría donde quedarían comprendidos, entre otros, ${ }^{51}$ los individuos que, en calidad de terroristas, pudiesen haber participado en las hostilidades.

Por este motivo, dentro del próximo apartado, realizaremos un estudio sobre aquellas personas que, en virtud de su supuesta participación en actos terroristas, han sido capturadas por alguna de las partes en el transcurso de las hostilidades, tratando de determinar cuáles podrían ser, en su caso, las normas jurídicas internacionales que ampararían y protegerían a los terroristas independientemente de su estatus jurídico.

\section{Las normas internacionales que protegen a los individuos implicados en actos de terrorismo internacional}

Dentro del presente estudio no pretendemos realizar un análisis sobre la problemática que, hasta ahora, la indeterminación jurídico-conceptual del terrorismo ha originado a la luz del derecho internacional, ya que tal propósito excedería los límites materiales de estas páginas. ${ }^{52}$

Nos centraremos, más bien, sólo en la cuestión relativa a la situación jurídica de las personas que, tras haber sido capturadas por alguna de las partes en el desarrollo de un conflicto armado, se presume su participación en actividades delictivas y terroristas.

Coincidiendo con lo señalado por la Comisión Interamericana de Derechos Humanos en su informe relativo al Terrorismo y Derechos Humanos, en ciertas circunstancias, las acciones terroristas y antiterroristas pueden comportar una violencia organizada de tal intensidad que dé lugar a un conflicto armado. Ese sería el caso, por ejemplo, en que las acciones terroristas y antiterroristas conllevan recurrir a la fuerza armada

51 Respecto a esos otros individuos que podrían encontrarse dentro de la categoría de combatientes ilegales, véase, entre otros, Montes Sánchez, M. R., "El estatuto jurídico de los espías, mercenarios, guerrilleros, desertores y saboteadores en el derecho internacional humanitario", Cuadernos de Derecho, Sevilla, UNED, núm. 4, 1990, p. 47.

52 Para un estudio en profundidad y una amplia bibliografía sobre el tema, véase Sottile, A., "Le terrorisme international", Recueil des Cours de l'Académie de Droit International, t. 64, 1938-II, pp. 87 y ss. Más recientemente: Alcaide Fernández, J., Las actividades terroristas ante el derecho internacional contemporáneo, Madrid, Tecnos, 2000, p. 375. Cfr., del mismo autor, "Derechos humanos y terrorismo: límite, fundamento y solución”, Cursos de Derechos Humanos de Donosti-San Sebastián, vol. V, 2004, pp. 11-48. 
en su caso, las normas jurídicas internacionales que ampararían y protegerían a los terroristas independientemente de su estatus jurídico.

\section{Las normas internacionales que protegen a los individuos implicados en actos de terrorismo internacional}

Dentro del presente estudio no pretendemos realizar un análisis sobre la problemática que, hasta ahora, la indeterminación jurídico-conceptual del terrorismo ha originado a la luz del derecho internacional, ya que tal propósito excedería los límites materiales de estas páginas..$^{52}$

Nos centraremos, más bien, sólo en la cuestión relativa a la situación jurídica de las personas que, tras haber sido capturadas por alguna de las partes en el desarrollo de un conflicto armado, se presume su participación en actividades delictivas y terroristas.

Coincidiendo con lo señalado por la Comisión Interamericana de Derechos Humanos en su informe relativo al Terrorismo y Derechos Humanos, en ciertas circunstancias, las acciones terroristas y antiterroristas pueden comportar una violencia organizada de tal intensidad que dé lugar a un conflicto armado. Ese sería el caso, por ejemplo, en que las acciones terroristas y antiterroristas conllevan recurrir a la fuerza armada entre los Estados (en este supuesto, estaremos en presencia de un conflicto armado internacional), o las hipótesis en que, dentro del territorio de un determinado Estado (en cuya situación, estaremos en presencia de un conflicto armado no internacional) existen enfrentamientos armados de baja intensidad y abiertos entre fuerzas o grupos armados relativamente organizados..$^{53}$

Cuando esta situación se presenta en la práctica — como sucedió en el conflicto armado internacional entre los Estados Unidos de América y Afganistán—, serán, precisamente, las normas del derecho internacional

52 Para un estudio en profundidad y una amplia bibliografía sobre el tema, véase Sottile, A., "Le terrorisme international", Recueil des Cours de l'Académie de Droit International, t. 64, 1938-II, pp. 87 y ss. Más recientemente: Alcaide Fernández, J., Las actividades terroristas ante el derecho internacional contemporáneo, Madrid, Tecnos, 2000, p. 375. Cfr., del mismo autor, "Derechos humanos y terrorismo: límite, fundamento y solución", Cursos de Derechos Humanos de Donosti-San Sebastián, vol. V, 2004, pp. 11-48.

53 Comisión Interamericana de Derechos Humanos, op. cit., nota 50, parágrafo 73. 
de los artículos 43 a 45 del Protocolo Adicional I, para los Estados que sean parte de este instrumento.

En este caso, el régimen de protección de los individuos no entrañaría una problemática mayor, ya que el hecho de que los miembros de esas fuerzas puedan haber participado en actos de terrorismo no alteraría la aplicación sistemática del derecho internacional humanitario al conflicto, ni el derecho de esos miembros a la protección del III Convenio de Ginebra o del Protocolo Adicional I cuando fuera aplicable. Es decir, independientemente de que estas personas hayan estado involucradas en actos de terrorismo, dicha situación no les impedirá gozar de los beneficios inherentes al estatuto de combatiente y de prisionero de guerra ${ }^{55}$ que prevén las normas del derecho internacional humanitario. Sin embargo, por su participación en actos de violencia terrorista, pueden ser procesados y puede determinarse la responsabilidad penal individual ${ }^{56}$ por actos de terrorismo, en la medida en que puedan constituir bien infracciones graves de los Convenios de Ginebra de 1949 o del Protocolo Adicional I, donde sea aplicable, o bien otra violación seria del derecho internacional humanitario..$^{57}$

El segundo de estos supuestos se presentaría cuando las personas que intervengan en un conflicto armado internacional, que presuntamente hayan participado en actos de terrorismo, no cumplan con los requisitos que les permitiría obtener el estatuto de combatiente y prisionero de guerra, pero, sin embargo, sí cumplan con el requisito de nacionalidad establecido en el artículo 4 del IV Convenio de Ginebra.

55 Para una relación detallada de los beneficios que implica la obtención del estatuto de combatiente y prisionero de guerra, véase el apartado III, epígrafes 1 y 2 del presente trabajo.

56 Respecto a la responsabilidad penal del individuo a la luz del derecho internacional, véase Abellán Honrubia, V., "La responsabilité internationale de l'individu", Recueil des Cours de l' Académie de Droit International, vol. V, t. 280, 1999, pp. 135 y ss.

57 Véase, por ejemplo, IV Convenio de Ginebra, artículo 33 (por el que se prohíbe "toda medida de intimidación o de terrorismo" en relación con personas protegidas), artículo 147 (incluyendo "la toma de rehenes" entre las graves violaciones, cuando son cometidas contra personas o bienes protegidos por el IV Convenio de Ginebra); Protocolo Adicional II, artículo 4(2)(d) (por el que se prohíben los "actos de terrorismo" en todo momento y en todo lugar), artículo 13 (por el que se prohíben "los actos o amenazas de violencia con el propósito primordial de sembrar el terror entre la población civil"). 
En tales circunstancias, serán consideradas personas civiles y, por tal motivo, contarán con la protección que las normas del IV Convenio de Ginebra establecen. Por lo tanto, tendrán derecho a gozar de una protección general contra los peligros que derivan de las operaciones militares; en particular, no deben ser objeto de ataque. Con excepción del caso, relativamente poco frecuente, de un levantamiento en masa, las personas civiles no tienen derecho a participar directamente en las hostilidades. Si lo hacen, siguen siendo civiles, pero se convierten en objetivos lícitos de ataque mientras dure su participación.

Cuando las personas protegidas por el IV Convenio de Ginebra pudiesen haber intervenido ilícitamente en las hostilidades y, tras su supuesta participación en actos terroristas, caigan en poder de alguna de las partes en conflicto, no dejarán de beneficiarse de la protección que dicho convenio les otorga.

En tercer y último lugar, nos encontraríamos en el supuesto de que las personas que intervengan en un conflicto armado internacional, sospechosas de haber participado en actos de violencia terrorista, no reúnan los requisitos que les permitiría obtener el estatuto de combatiente y prisionero de guerra a la luz del III convenio, ni cumplan con las exigencias de nacionalidad determinadas en el artículo 4 del IV convenio para ser consideradas como civiles y, por lo tanto, personas protegidas por las normas del derecho internacional humanitario contenidas en los convenios III y IV de Ginebra.

En este caso, estaríamos en presencia de los denominados combatientes ilegales o no privilegiados a los que hacíamos referencia en el apartado anterior del presente trabajo.

Cuando los individuos que pertenecen a esta categoría, supuestamente hayan participado en actos de violencia terrorista y caigan en poder de alguna de las partes enfrentadas dentro de un conflicto armado internacional - como es el caso del conflicto surgido en tierras afganas- podrán ser procesados por dichos actos. Sin embargo, no quedarán desprovistos de la protección que el derecho internacional otorga a todas las personas que han participado en, o se ven afectadas por, determinado acto de violencia.

En este sentido, las personas que no gozan de un trato más favorable en virtud de los Convenios de Ginebra, al margen de que hayan participado en actos de terrorismo, cuentan con el amparo y protección de las normas que integran el marco jurídico internacional de las personas que 
intervienen en los actos de violencia. Como manifiesta el profesor Cassese, cuya opinión compartimos, los derechos y privilegios asignados por el derecho internacional "no son materia de restricciones por la alegada actividad terrorista de los detenidos. Los actos terroristas, si son probados, sólo dan lugar a que los terroristas sean responsables de crímenes de guerra o de crímenes contra la humanidad". ${ }^{58}$

En efecto, independientemente de que los individuos que no cuenten con la autorización para participar en las hostilidades, y que hayan podido estar implicados en la comisión de actos terroristas, puedan ser procesados en virtud de la responsabilidad penal individual originada por los delitos a que su conducta pudiese haber dado lugar, ${ }^{59}$ se beneficiarán, particularmente, de las garantías contenidas en el artículo 3 común a los Convenios de Ginebra, ${ }^{60}$ de la protección derivada de la cláusula Mártens ${ }^{61}$ y del artículo 75 del Protocolo Adicional I, considerado como expresión de una norma de derecho internacional consuetudinario, ${ }^{62}$ puesto que las anteriores disposiciones representan un estándar mínimo de protección respecto al "núcleo duro" de los derechos humanos.

La intangibilidad de estos derechos supone que los mismos no pueden ser suspendidos bajo ningún motivo o circunstancia y que son, por

58 Cassese, A., Terrorism and Human Rights citado por Comisión Interamericana de Derechos Humanos, op. cit., nota 50, parágrafo 20.

59 Respecto a la responsabilidad penal del individuo en el derecho internacional, véanse entre otros: Abellán Honrubia, V., op. cit., nota 56, pp. 135 y ss.; Sunga, L., Individual responsibility in international Law for serious human rights violations, Dordrecht, Martinus Nijhoff Publishers, 1992, pp. 140 y ss.

60 Para un estudio sobre la protección que este artículo otorga a las personas como parte del derecho internacional consuetudinario, véase entre otros: Carrillo Salcedo, J. A., op. cit., nota 7, pp. 145 y ss.

61 Para un mayor abundamiento sobre la protección que dicha cláusula ofrece a las personas como parte del derecho internacional consuetudinario, véanse entre otros: Cassese, A., "The Mártens clause: Half a loaf or simple pie in the sky?", European Journal of International Law, vol. 11, 2000, pp. 187 y ss.; Petit de Gabriel, E. W., Las exigencias de humanidad en el derecho internacional tradicional (1789-1939), Madrid, Tecnos, 2003, pp. 152 y ss.; Pustogarov, V., "The Mártens clause in International Law", Journal of the History of International Law, 1999, pp. 125 y ss.; Ticehurst, R., "La cláusula Mártens y el derecho de los conflictos armados", Revista Internacional de la Cruz Roja, núm. 140, 1997, pp. 131 y ss.

62 Pozo Serrano, P., op. cit., nota 5, p. 195. En el mismo sentido, véanse Human Rights Watch, op. cit., nota 5; Pérez González, J. L. y Rodríguez-Villasante y Prieto, J. L., op. cit., nota 5, p. 30 . 
otra parte, válidos para todas las personas, sin importar el estatus jurídico que posean o los delitos que hubieran podido cometer. Como señala el relator especial de la Comisión de Derechos Humanos, Leandro Despouy, en su informe titulado Los Derechos Civiles y Políticos, en Particular las Cuestiones Relacionadas con la Independencia del Poder Judicial, la Administración de Justicia y la Impunidad, ${ }^{63}$ "no existe en el orden jurídico internacional vigente la posibilidad de sustraer a una persona de la aplicación de dichas normas. Esto es así con independencia de la calificación jurídica que se emplee, ya sea, combatiente ilegal, subversivo, terrorista, u otra". ${ }^{64}$

Por lo tanto, las personas sospechosas de haber cometido actos de terrorismo, que hayan caído en manos de algún Estado beligerante, al margen del estatus jurídico que se les atribuya, o cuando no se les atribuye estatuto alguno, se beneficiarán, por lo menos, de aquellas normas intangibles del derecho internacional que otorgan un mínimo jurídico de protección, basado en las consideraciones elementales de humanidad, que garantizan un trato humano para todas las personas que se encuentren sujetas a cualquier forma de detención, sin importar que hayan podido cometer alguno de los delitos más graves, dentro de los cuales, entraría, sin duda alguna, el terrorismo internacional. ${ }^{65}$

Por lo tanto, nadie en manos del enemigo, incluyendo, desde luego, a los propios terroristas, se encuentra al margen de la ley.

63 En dicho informe, el relator especial se ocupa de dos cuestiones de actualidad, a saber, los efectos de la lucha contra el terrorismo sobre los derechos humanos y la administración de justicia durante los periodos de transición. En cuanto al primer tema, se propone la realización de un estudio para averiguar si las leyes y demás medidas adoptadas por los Estados para luchar contra el terrorismo o preservar la seguridad nacional son compatibles con las normas del derecho internacional. Con respecto a la justicia durante los periodos de transición, el relator especial propone que la Comisión de Derechos Humanos profundice sobre la cuestión con el fin de que los Estados en transición dispongan rápidamente de las herramientas y referencias que se estén preparando para ayudarles a responder a las cuestiones con que se enfrentan en relación con la justicia, la lucha contra la impunidad y el derecho de las víctimas a la verdad, la reparación y la indemnización.

64 Parágrafo núm. 35 del informe del relator especial sobre la independencia de los magistrados y abogados, Comisión de Derechos Humanos, de fecha 20 de enero de 2005, documento E/CN.4/2005/60. Las cursivas son mías.

65 Respecto a las conductas consideradas como delictivas a la luz del derecho internacional, véase por ejemplo Rueda Fernández, C., Delitos de derecho internacional, Barcelona, Bosch, 2001, p. 320. 


\section{CONCLUSIONES}

Al finalizar estas páginas, varias ideas pueden servir para resumir lo expuesto en el presente estudio:

Primera. Para la comunidad internacional, la implacable guerra contra el terrorismo, originada a raíz de los lamentables atentados perpetrados el 11-S de 2001, ha constituido una fuente inagotable de preocupaciones, sobre todo en lo relativo a la observancia de la legalidad internacional, a la aplicación de las normas del derecho internacional humanitario a los conflictos armados y al respeto de los derechos humanos fundamentales de la persona humana.

El caso de las personas detenidas por las fuerzas armadas de la coalición que, desde hace más de cuatro años, se encuentran recluidas en la prisión estadounidense de Guantánamo y, probablemente, en otras prisiones secretas dispersas por el mundo, sin cargos y sin haber gozado de un juicio previo, privadas del acceso a los tribunales, de asistencia letrada, de comunicación con sus familiares y hasta hace muy poco en el anonimato, es un claro ejemplo de que, en el marco de la "guerra contra el terrorismo", la legalidad internacional, el Estado de derecho y el respeto irrestricto de los derechos humanos fundamentales, se encuentran subordinados a la lógica militar y a las necesidades de seguridad que, de manera unilateral, han alegado las autoridades estadounidenses en su lucha contra la violencia terrorista.

Precisamente, la confusa situación en la que se encuentran las personas recluidas en dicha base militar, ha generado una enorme alarma a nivel internacional. Ha sido, y sigue siendo, el centro de debate de un gran número de trabajos doctrinales, ha motivado la intervención de organismos internacionales y ha provocado la movilización de numerosas organizaciones protectoras de los derechos humanos a nivel mundial.

Segunda. El derecho internacional contemporáneo otorga una protección a todas aquellas personas que participan en un determinado acto de violencia, independientemente de la calificación que dicho acto pueda tener a la luz del derecho internacional e interno de cada Estado. Como hemos podido constatar a lo largo de estas líneas, el marco jurídico que regula la participación de las personas en un determinado acto de violencia, está integrado, en su aspecto convencional, por las normas del derecho internacional de los conflictos armados y, de manera supletoria, por aquellas disposiciones normativas del derecho internacional de los dere- 
chos humanos que tengan la calidad de inderogables o intangibles. En su aspecto consuetudinario, dicho marco jurídico se integraría por todas aquellas disposiciones de naturaleza consuetudinaria, incluidos los principios generales del derecho internacional, que constituyan un estándar mínimo de protección respecto al "núcleo duro de los derechos humanos", cuyo respeto es obligatorio para todos los Estados al margen de cualquier vínculo convencional.

Cuando la violencia terrorista origine un conflicto armado y, durante el mismo, se capturen a los presuntos responsables de haber participado en actos de terrorismo internacional, podemos afirmar que dichas personas si pertenecen a las fuerzas armadas de alguna de las partes y cumplen con las exigencias del III Convenio de Ginebra, tendrán derecho a gozar de los beneficios inherentes al estatuto de combatiente y de prisionero de guerra que prevén las normas del derecho internacional humanitario. Esta situación no excluirá que puedan ser procesadas en virtud de la responsabilidad penal individual que los actos de terrorismo que les son imputados pudiesen haber originado, en la medida en que puedan constituir bien infracciones graves de los Convenios de Ginebra de 1949 o del Protocolo Adicional I, o bien otra violación seria del derecho internacional humanitario.

Tercera. Por otra parte, cuando las personas detenidas, presuntamente responsables de haber cometido un acto de terrorismo, no cumplen con los requerimientos que les permitiría obtener el estatuto de combatiente y prisionero de guerra, pero, sin embargo, sí cumplen con el requisito de nacionalidad establecido en el artículo 4 del IV Convenio de Ginebra, serán consideradas como personas civiles y, por lo tanto, no dejarán de beneficiarse de la protección que dicho convenio les otorga.

Por último, cuando los presuntos terroristas hayan sido detenidos durante el transcurso de un conflicto armado, y no reúnan los requisitos que les permitiría obtener el estatuto de combatiente y prisionero de guerra a la luz del III Convenio de Ginebra, ni cumplan con las exigencias de nacionalidad determinadas en el artículo 4 del IV convenio para ser considerados como civiles, podrán ser juzgados y sancionados por su beligerancia no privilegiada. No obstante, dichas personas seguirán contando con la protección que el derecho internacional ofrece a todas las personas que intervienen o se ven afectadas por una situación concreta de violencia. 
Particularmente, se beneficiarán de las garantías contenidas en el artículo 3 común a los Convenios de Ginebra, de la protección derivada de la cláusula Mártens y del artículo 75 del Protocolo Adicional I, considerado como expresión de una norma de derecho internacional consuetudinario, toda vez que las anteriores disposiciones representan un estándar mínimo de protección respecto al "núcleo duro" de los derechos humanos y, por lo tanto, son oponibles a todos los Estados al margen de cualquier vínculo convencional.

Cuarta. En este sentido, podemos llegar a la conclusión final de que nadie en poder de una parte enemiga, que haya sido detenido durante el transcurso de un acto de violencia, se encuentra al margen de la protección que las normas del derecho internacional prevén, independientemente de los actos o delitos que pudiese haber cometido, nadie se encuentra al margen de la ley y la legalidad internacional. 
Particularmente, se beneficiarán de las garantías contenidas en el artículo 3 común a los Convenios de Ginebra, de la protección derivada de la cláusula Mártens y del artículo 75 del Protocolo Adicional I, considerado como expresión de una norma de derecho internacional consuetudinario, toda vez que las anteriores disposiciones representan un estándar mínimo de protección respecto al "núcleo duro" de los derechos humanos y, por lo tanto, son oponibles a todos los Estados al margen de cualquier vínculo convencional.

Cuarta. En este sentido, podemos llegar a la conclusión final de que nadie en poder de una parte enemiga, que haya sido detenido durante el transcurso de un acto de violencia, se encuentra al margen de la protección que las normas del derecho internacional prevén, independientemente de los actos o delitos que pudiese haber cometido, nadie se encuentra al margen de la ley y la legalidad internacional. 